\title{
Effets de l'extrusion du pois (Pisum sativum) sur le flux intestinal d'azote chez la vache
}

\author{
M Focant, A Van Hoecke, M Vanbelle \\ Université Catholique de Louvain, Faculté des Sciences Agronomiques, \\ Unité de Biochimie de la Nutrition, 3, Place Croix du Sud, B-1348 Louvain-la-Neuve, Belgique
}

\begin{abstract}
Summary - Six Friesian heifers fed a $40 \%$ pea diet were used in a cross-over design. Ground and extruded peas were compared. Decreased nitrogen $(N)$ solubility produced by extrusion was associated with an increase in non-ammonia- $N$ flow (+ 36\%; $\mathrm{P}<0.001)$ resulting from improvements in bacterial $N$ flow (+ 53\%; $P<0.01$ ) and in feed $N$ flow ( $+19 \% ; P>0.05)$.
\end{abstract}

Introduction - L'utilisation du pois protéagineux (Pisum sativum) par les bovins est limitée par la grande solubilité de ses protéines. Cependant, un traitement thermique approprié appliqué aux graines peut réduire la dégradation des protéines dans le rumen (Hale, 1973). Ainsi, l'extrusion des graines de soja (Stern et al, 1985) ou des graines de coton (Pena et al, 1986) permet d'accroître le flux intestinal d'azote. Nous avons mesuré, chez la vache, l'effet de l'extrusion du pois sur le flux d'azote au niveau du duodénum.

Matériel et Méthodes - Six génisses Frisonnes, d'un poids moyen de $546 \mathrm{~kg}$, munies d'une canule du rumen et d'une canule simple duodénale, ont été utilisées dans un schéma expérimental en "cross-over". Elles ont reçu, chaque jour, $2,5 \mathrm{~kg}$ de pulpes déshydratées de betterave, $1,8 \mathrm{~kg}$ de paille de blé hachée, $0,3 \mathrm{~kg}$ d'un complément minéral vitaminé et $3 \mathrm{~kg}$ de pois moulu ou extrudé, en 2 repas distribués à 9:00 h et à 16:00 h. L'extrusion à sec a été réalisée dans les installations de la société Royal Canin (Cambrai, France) par un extrudeur bi-vis de marque Clextral. La dégradabilité des protéines par la pepsine et la biodisponibilité de la lysine (Vervack et al, 1976) ont été mesurées. La dégradation in vitro des matières azotées a été déterminée après une incubation de $6 \mathrm{~h}$ a $40^{\circ} \mathrm{C}$ dans un mélange tampon phosphate/ liquide de rumen de bovin dans le rapport 4/1. L'oxyde de chrome, le polyéthylène glycol et l'acide diaminopimélique ont été utilisés respectivement comme marqueurs de la phase solide, de la phase liquide et des protéines bactériennes. Le flux du chyme duodénal a été mesuré sur tous les animaux et sur $2 \mathrm{j}$ selon la méthode décrite par Faichney (1975).

Résultats et Discussion - L'extrusion du pois a diminué la dégradabilité in vitro des matières azotées (29 au lieu de 69\%). Cette insolubilisation des protéines dans le liquide de rumen n'a pas été associée à une moindre digestion par la pepsine ni à une moins bonne biodisponibilité de la lysine (tableau I).

Tableau I. Caractéristiques des protéines dụ pois.

Pois Pois moulu extrudé

$N \times 6,25(\%$ MS)

$24,4 \quad 27,3$

$\mathrm{N}$ dégradé par la.pepsine (\% N) $96,5 \quad 94,2$

Lysine disponible (\% lysine) $\quad 92,3 \quad 95,0$

$\mathrm{N}$ dégradé in vitro $(\% \mathrm{~N}) \quad 68,8 \quad 28,6$ 
Tableau Il. Effets de l'extrusion du pois sur le flux duodénal d'azote chez la vache $(n=6)$.

\begin{tabular}{lccc}
\hline \multicolumn{1}{c}{ Régime } & Pois moulu & Poids extrudé & P \\
\hline Mat organ ingérée $(g / j)$ & 6215 & 6282 & - \\
$\mathrm{N}$ ingéré $(g / j)$ & 146 & 162 & \\
Flux de $\mathrm{N}$ non $\mathrm{NH}_{3}(g / j)$ & $136 \pm 11$ & $185 \pm 9$ & $<0,001$ \\
Flux de $\mathrm{N}$ bactérien & $68 \pm 11$ & $104 \pm 13$ & $<0,01$ \\
Flux de $\mathrm{N}$ alim \& endogène & $68 \pm 15$ & $81 \pm 10$ & $<0,05$ \\
Prot bact $(g / 100 \mathrm{~g}$ MOD) & $11 \pm 2$ & $17 \pm 2$ & $<0,01$ \\
\hline
\end{tabular}

Le flux d'azote non ammoniacal au niveau du duodénum est augmenté de $36 \%$ par l'extrusion $(P<0,001)$. Ceci confirme pour le pois, les résultats obtenus pour le soja (Stern et al, 1985) et pour le coton (Pena et al, 1986). MichaletDoreau et al (1987) n'avaient pas observé de modification du flux de $\mathrm{N}$ au niveau duodénal par l'extrusion de graines de colza. Dans notre expérience, le plus grand flux de $\mathrm{N}$ non $\mathrm{NH}_{3}$, enregistré pour le régime "pois extrudé", résulte d'un accroissement de $53 \%$ du flux de $\mathrm{N}$ bactérien et de $19 \%$ du flux de $\mathrm{N}$ alimentaire.

En conclusion, l'extrusion du pois permet d'accroître, chez la vache, les quantités d'acides aminés entrant dans l'intestin grêle. Cette amélioration résulte de la plus faible dégradation des protéines alimen- taires et de la meilleure efficience de la synthèse microbienne dans le rumen.

Remerciements - Travail subventionné par I'IRSIA, rue de Crayer, 6, B-1050 Bruxelles, et par la Soc Coop INTERAGRI, Parc Industriel, B5210 Seilles.

Faichney GJ (1975) In: Proc 2nd int Symp Rumin Physiol (McDonald IW, Warner ACl, eds) Univ New England, Armidale, Australia

Hale WH (1973) J Anim Sci 37, 1075-1083

Michalet-Doreau B, Doreau M, Voisin A, Bogaert C (1987) in: Cuisson-extrusion (Les Colloques de l'INRA, $n^{\circ} 41$ ), INRA, Paris

Pena F, Tagari H, Satter LD (1986) J Anim Sci $62,1423-1433$

Stern MD, Santos KA, Satter LD (1985) J Dairy Sci 68, 45-56

Vervack W, Vanbelle M, Foulon M (1976) Rev Ferment ind Alim Bruxelles 31, 143-146 